Please do not remove this page

RMIT

UNIVERSITY

\title{
Are we on the same page? Exploring construction professionals' mental models of occupational health and safety
}

Lingard, Helen; Zhang, Peihua; Blismas, Nick; Wakefield, Ronald; Kleiner, Brian

https://researchrepository.rmit.edu.au/esploro/outputs/9921862388601341/filesAndLinks?institution=61RMIT_INST\&index=null

Lingard, H., Zhang, P., Blismas, N., Wakefield, R., \& Kleiner, B. (2015). Are we on the same page? Exploring construction professionals' mental models of occupational health and safety. Construction Management and Economics, 33(1), 73-84. https://doi.org/10.1080/01446193.2015.1016541

Document Version: Accepted Manuscript

Published Version: https://doi.org/10.1080/01446193.2015.1016541

Repository homepage: https://researchrepository.rmit.edu.au

(C) 2015 Taylor \& Francis

Downloaded On 2023/04/26 23:02:07 +1000

Please do not remove this page 
Thank you for downloading this document from the RMIT Research Repository.

The RMIT Research Repository is an open access database showcasing the research outputs of RMIT University researchers.

RMIT Research Repository: http://researchbank.rmit.edu.aul

\section{Citation:}

Lingard, H, Zhang, P, Blismas, N, Wakefield, R and Kleiner, B 2015, 'Are we on the same page? Exploring construction professionals' mental models of occupational health and safety', Construction Management and Economics, vol. 33, no. 1, pp. 73-84

See this record in the RMIT Research Repository at:

https://researchbank.rmit.edu.au/view/rmit:34164

Version: Accepted Manuscript

Copyright Statement:

(C) 2015 Taylor \& Francis

Link to Published Version:

http://dx.doi.org/10.1080/01446193.2015.1016541 


\title{
Are we on the same page? Exploring construction professionals' mental models of occupational health and safety
}

\author{
Lingard, H, Zhang, P, Blismas, N, Wakefield, R and Kleiner, B
}

\begin{abstract}
Photographic Q-methodology was used to explore construction professionals' mental models of occupational health and safety (OHS). Sixty Australian construction professionals participated in the research, including 15 architects, 15 engineers, 15 constructors and 15 OHS professionals. Participants were asked to sort photographs depicting different building systems into a grid based upon their judgement of the likelihood of accidental injury resulting from the construction of each of the building systems depicted. Responses ranged from Rare (-2) to Certain (+2). Sorting patterns relating to eight photographs of different façade systems were analysed using Qfactor analysis. Three distinct sorting pattern types were identified in the data, representing clusters of participants whose sorting patterns were similar. These sorting pattern types cut across occupational/professional groups. Interpretation of the factors revealed substantial differences between the OHS judgements made by participants in the three clusters. Qualitative explanatory information revealed participants in the three clusters used different attributes when considering the likelihood of accidental injury. These attributes shaped their sorting patterns. The results suggest shared mental models (SMMs) are unlikely to exist in construction project teams, as each individual uses their own frame of reference to understand OHS. Opportunities exist to understand these different frames of reference and create more consistent team mental models of OHS. However, incorporating a diversity of viewpoints into project decision-making is recommended in order to produce effective decision-making in the choice or specification of building systems.
\end{abstract}

\section{Keywords}

Occupational health and safety, shared mental models, façade systems, distributed teams, Qmethodology

\section{Introduction}

The organisational environment of construction projects

Construction projects are delivered by temporary, multidisciplinary and multi-organisational teams. Salas et al. (1992) define a team as "a distinguishable set of two or more people who interact dynamically, interdependently, and adaptively toward a common and valued goal/objective/mission, who have each been assigned specific roles or functions to perform, and who have a limited life-span of membership" (p. 4). Due to the ad hoc nature of project teams, in which individuals are brought together for a single project then disband once the project is complete, team members need to quickly form a shared understanding of goals, tasks and the performance environment, while possessing limited knowledge of other team members' capabilities and work styles (Resick et al. 2010). In this context, effective coordinating mechanisms are particularly important.

Construction project teams are also usually geographically separated, or distributed.

Distributed teams are defined as those "where several individuals may be co-located but other clusters of team members work in other locations" (Stagl et al. 2007). Consequently much interaction between members in distributed teams occurs electronically rather than face-toface (Driskell et al. 2003). Distributed teams present additional coordination challenges as there are fewer opportunities to monitor team members' behaviour and provide feedback. Fewer opportunities to observe non-verbal cues can also create ambiguity and reduced situation awareness in members (Fiore et al. 2003). Added to this, construction work is often undertaken under conditions of time pressure, with severe financial penalties for time overruns. Not surprisingly, construction professionals are reported to experience considerable stress (Leung et al. 2008; Bowen et al. 2013), which can cause people to lose the team 
perspective and become narrowly focused on their own task performance (Driskell et al. 1999). This type of organisational climate is not conducive to creating a shared vision among the project team.

\section{Shared mental models as a coordinating mechanism}

Researchers have begun to examine the role played by shared mental models (SMMs) as a coordinating mechanism in teams (Salas et al. 2005). Mental models are defined as "mechanisms whereby humans are able to generate descriptions of system purpose and form, explanations of system functioning and observed system states and predictions of future system states" (Rouse \& Morris, 1986, p.351). SMMs within teams refer to an organised understanding or mental representation of knowledge shared by team members (CannonBowers et al. 1993). There is a growing body of evidence to indicate that SMMs in project teams improves team performance by enabling enhanced and effective coordination (Mathieu et al., 2000, Klimoski and Mohammed, 1994, Banks \& Millward, 2007). In particular, implicit coordination is reported to mediate the relationship between team members' SMMs and performance (Fisher et al., 2012). Thus, it is argued that teams are most effective when members are able to anticipate and predict other members' needs, identify changes in the task or team and adjust their strategy as needed. However, in order to do this team members need to share similar mental models of the system in which they are operating (Espevik et al. 2011).

\section{Different types of shared mental models}

Research has investigated the coordination and team performance benefits flowing from different types of SMM, including SMMs relating to equipment to be deployed, the task at hand and team interaction (Stout et al. 1999). For example, Espervik et al. (2011) investigated the benefits associated with SMMs relating to team members' knowledge, skills, attitudes and preferences and found that teams that were very familiar with one another's individual attributes demonstrated higher levels of coordination and performance in high workload situations. Mathieu et al. (2005) report that SMMs relating to the task at hand, produce better team processes and performance outcomes. Other researchers have distinguished between task and team SMMs and note that team-focused SMMs are more strongly predictive of team processes whereas task-focused SMMs more strongly predict specific performance outcomes (De Church \& Mesmer Magnus, 2010). Many facets of team and task performance have been measured in studies investigating the effects of SMMs. Some of these studies have identified positive safety performance associated with team SMMs (see, for example, Smith-Jentsch et al. 2005).

To date, little empirical research has empirically investigated the presence of SMMs specifically relating to occupational health and safety (OHS). However, it is possible that SMMs reflecting OHS perceptions, attitudes, priorities and expectations develop within teams, and these may have important implications for OHS performance.

\section{Aim}

The research empirically explored the mental models of OHS held by a diverse sample of construction industry professionals. Specific research objectives were:

(i) to use a photographic Q-methodology approach to explore and understand the OHS mental models of a diverse sample of construction industry professionals,

(ii) to explore patterns of similarity and difference in mental models of OHS within and between participants in the research, and

(iii)to examine the qualitative attributes used by participants in thinking about OHS risk. 
The remainder of this paper is organised as follows. The potential importance of SMMs in securing a more integrated and effective way to manage OHS in construction project teams is discussed. The photographic Q-methodology and analytical procedures used in the research are described. The research results are presented. The implications flowing from the research results are discussed in terms of the potential usefulness of understanding team members' mental models relating to OHS, and the possible benefits associated with implementing strategies to develop SMMs of OHS in construction project teams. Lastly, conclusions relating to future research directions and practical implications of the research are drawn.

\section{Integrating OHS into construction projects - structural challenges}

There has been a significant policy push to require construction industry participants to integrate OHS considerations into all project decision-making, from the initial planning and design of a facility through the construction to the eventual commissioning and handover of the end product. Consequently, OHS legislation in many jurisdictions establishes specific OHS responsibilities for construction clients and those engaged in the planning and design of buildings or structures for construction. Yet fundamental challenges exist to the integration of OHS into decision-making throughout the project life-cycle. For example, a review of OHS in the UK construction industry identified separation and poor communication between designers and constructors as a persistent cause of construction fatalities (Donaghy, 2009).

Fragmentation in the construction supply chain can militate against effective teamwork. Lawrence and Lorsch (1969) describe how too much differentiation in production systems can prohibit the establishment of a "common purpose." Vertical segregation between participants engaged in the initiation, design, production, use and maintenance of facilities has been noted as an impediment to effective teamwork (Atkinson \& Westall, 2010) and the development of shared project goals (Baiden \& Price, 2011). Indeed, fragmented supply arrangements, resulting in communication and coordination failures between professional contributors in different phases of the project lifecycle (i.e, planning, design and construction) have been identified as a critical factor in the emergence of serious safety problems in construction projects (Priemus \& Ale, 2010).

Prussia et al. (2003) identify the development of SMMs, relating to OHS, as being important in achieving a common purpose and improving OHS performance in an organisational environment. Espevik et al. (2011) argue that SMMs enable team members to draw on their own mental models as the basis for choosing actions that are consistent and coordinated with other team members. This is likely to be particularly important in a dynamic project environment in which behaviour needs to be adapted in response to unfolding events and new information inputs (Waller et al. 2004).

Previous research in the construction industry suggests an absence of SSMs relating to OHS For example, Gherardi et al. (1998) describe how the diverse functional groups that contribute to construction projects differ in their cognitive and emotional orientation towards OHS. Richter and Koch (2004) similarly describe how social groups within a single construction organisation develop distinctive subcultures in relation to the pursuit of organisational goals, e.g. production, cost, functionality, constructability and OHS.

Given the potential benefits associated with the development of SSMs in construction project teams, there is significant value in examining ways in which construction industry 
participants' mental models of OSH can be explored so that points of similarity and difference can be identified, understood and managed.

\section{Research methods}

\section{Data collection}

Q-methodology is ideally suited to the study of SMMs because it is used to reveal participants' cognitive structures, attitudes, and perceptions (Anandarajan et al., 2006). Qmethodology requires participants to put a sample of objects (known as a Q-set) into a rank order according to some predetermined instruction. When the objects are arrayed into categories, the resulting pattern is called a Q-sort. A Q-sort is then taken to be a reflection of a participant's subjective views about the phenomenon under investigation (Brown 1993).

Photographs printed onto laminated cards were used as stimuli for the sorting task.

Photographs have been effectively used as stimuli for Q-sorting in landscaping studies (see, for example, Green, 2005, Fairweather et al., 1998). Card sorting has also previously been used to explore mental models (Smith-Jentsch et al. 2001). The photographs represented different systems used for the construction of four typical building elements (i.e, facades, roofs, structures and services). Consistent with the requirements of Q-methodology, the photos were broadly representative of different building systems and their inherent OHS implications (Stenner et al., 2008; Watts \& Stenner, 2005). Prior to collecting the data, photographs were subjected to a pilot validation (using industry representatives) to ensure that the images were representative and also provided sufficient information for participants to make judgements about OHS issues. Eight photographs were retained for each building element. As an example, Table 1 provides a description of the eight façade systems represented by the photographs.

Table 1: Photograph codes and descriptions

\begin{tabular}{ll}
\hline Photo ID & Descriptions \\
\hline F01 & Precast concrete panel system for housing \\
F02 & Precast concrete panel system for car park \\
F03 & Concrete and window panel façade system \\
F04 & Full storey prefabricated façade system \\
F05 & Glazed panel façade system \\
F06 & Mixed glass and concrete panel façade system. Note: concrete sections covered by glass \\
& panels \\
F09 & In-situ reinforced concrete walling \\
F10 & Concrete block wall façade system \\
\hline
\end{tabular}

It is common practice within Q-methodology studies to include some statements that are ambiguous or contain multiple possible meanings (Dryzek \& Berejikian 1993, Brown 1970). Thus photographs could represent different types of OHS hazard/risk at the same time, e.g. fall from height, collision with a vehicle or plant or ergonomic issues. Unlike questionnairebased research, Q-sort stimuli are not required to have a single, unambiguous meaning set by the researcher. Rather, the stimuli are intended to reveal different subjective perspectives on the same issue. Thus, stimuli eliciting multiple possible interpretations add to the richness of data.

Participants were initially asked to sort the photographs into a grid according to their evaluation of the likelihood of an accidental injury arising during the construction of the depicted building system. The grid contained five columns with a rating scale ranging from “- 
2 Rare" to "+2 Almost certain". Once participants had completed the sorting task, they were asked to give reasons for their sorting pattern, i.e, to explain why they believed some systems presented a greater likelihood of accidental injury than others. This qualitative data was audio- recorded.

\section{Sampling strategy}

Data was collected from four professional groups involved in the delivery of construction projects, i.e, architects, engineers, constructors, and OHS professionals. All participants were practising professionals in the Australian construction industry at the time of data collection. Q-methodology does not require a large number of participants and typically participants are not randomly sampled but purposefully selected based on their familiarity with the topic (Watts \& Stenner, 2005, Brown 1980). In Q-methodology, diversity of opinion is a more important participant selection principle than the extent to which participants represent the larger population from which they are drawn because this allows different subjective viewpoints to be revealed and explored. Stainton Rogers (1995) suggests that to reflect an appropriate breadth and diversity of viewpoints a participant group containing between 40 and 60 participants is appropriate.

In this study 15 participants were invited from each professional group, making a total of 60 participants. The participants were mainly approached through the researchers' personal networks and a "snowball" sampling strategy was adopted whereby participants identified prospective participants who were contacted until the target sample size of 15 participants per professional group was reached. The snowball strategy was deemed to be appropriate as an important factor in Q-methodology is that participants are familiar with, and have "wellformed opinions" about a topic (Webler et al., 2009, p9).

\section{Data analysis}

The Q-methodology data collection produced both quantitative (i.e, the rank orderings of photos) and qualitative (i.e, the explanatory information) data. Data collected in this way is typically analysed using factor analysis to look for patterns in ways of thinking about the topic. Interview data is then used to aid the interpretation of the observed patterns in the data, and to develop insight into participants' different processes of framing the topic in question. The initial analysis was undertaken using the following steps:

- each person's rank-ordered sort of statements were initially transformed into an array of numerical data,

- each person's array of numerical data was then inter-correlated with the arrays of all the others,

- the resulting correlation matrix revealed which participants sorted the statements into similar orders,

- the correlation matrix was then subjected to factor analysis to obtain groupings of data arrays that were highly correlated.

The resulting factors represent clusters of participants with similar opinions about the topic (Fairweather et al., 1998), in this case the extent to which the building systems presented a greater or lesser risk of accidental injury.

The factor analysis was conducted using principal components analysis with varimax rotation, as recommended by Watts and Stenner (2005). Participants were deemed to belong to a factor or cluster if their Q-sort significantly loaded on that factor. A significant factor loading at the 0.05 level was calculated using the equation: $1.96 \times(1 \div \sqrt{ }$ no. of items in $\mathrm{Q}$ 
set) (Watts \& Stenner, 2012). Given the number of photographs in each photo set is 8 , a significant factor loading was deemed to be $1.96 \times(1 \div \sqrt{ } 8)=0.693$.

Weighted averages ( $Z$ scores) were calculated for each photograph. $Z$ scores are normalized factor scores calculated by PQ Method software for each individual photograph during the factor estimate process (for further details see, Watt and Stenner, 2012; p207). These scores reflect the level of agreement and disagreement that each photograph receives within each of the participant clusters arising from the factor analysis. As the numbers of Q-sorts that significantly loaded on each cluster were different, normalized factor scores (i.e. Z scores) were needed in order to perform cross-factor comparisons for each photograph. These scores were used to generate factor arrays for each cluster of participants. Watts \& Stenner (2012) describe a factor arrays as "a single Q sort configured to represent the viewpoint of a particular factor" (p. 140). The factor arrays were compared to identify points of difference within participant clusters.

Finally, qualitative data capturing participants' explanations about why they sorted the photographs in the manner they did was subjected to thematic content analysis. This analysis explored the attributes that they consider when making judgements about the inherent "riskiness" of a particular building system relative to alternative building systems.

\section{Results}

The results of the façade system Q-sort analysis are presented and discussed in the remainder of this paper.

\section{The sample}

Table 2 summarises participants in terms of their occupation and years of experience working in the construction industry.

\section{Table 2: Participants' professional experience}

\begin{tabular}{|l|c|c|c|c|c|}
\hline $\begin{array}{c}\text { Occupational } \\
\text { group }\end{array}$ & Number & $\begin{array}{c}\text { Min. years of } \\
\text { experience }\end{array}$ & $\begin{array}{c}\text { Max. years of } \\
\text { experience }\end{array}$ & $\begin{array}{c}\text { Mean years of } \\
\text { experience }\end{array}$ & SD \\
\hline Architect & 15 & 3 & 40 & 21.7 & 15.9 \\
\hline Engineer & 15 & 2 & 38 & 16.2 & 12.2 \\
\hline $\begin{array}{l}\text { OHS } \\
\text { professional }\end{array}$ & 15 & 7 & 44 & 21.9 & 10.4 \\
\hline Constructor & 15 & 2 & 37 & 18.0 & 9.5 \\
\hline
\end{tabular}

\section{Factor analysis}

Among the Q-sorts of the 60 participants, data from four participants (two engineers, one architect and one constructor) was removed from the analysis because these participants sorted all the photographs into a single column. These sorts were considered to be invalid and excluded from the analysis as they suggest the participants did not attempt to cognitively differentiate the likelihood of accidental injury represented in each photograph. Also, Q factor analysis is based on variance analysis and a Q-sort with all photographs sorted in the same column does not produce any variance and cannot be analysed in this way.

The remaining 56 sorting patterns were subjected to the analytical procedures previously described. The factor analysis produced a parsimonious model of three factors that represented different construction professional views regarding the likelihood of accidental 
injury arising during the construction of the façade systems represented in the Q-set photographs. These three opinion types explained $31 \%, 21 \%$ and $19 \%$ of the total variance respectively. Thus the three factor solution explained a total of $71 \%$ of the variance in the sample.

Among the 56 sorts, 15 sorts (26.8\%) significantly loaded on factor one, eight sorts $(14.3 \%)$ significantly loaded on factor two, and another nine sorts $(16.1 \%)$ significantly loaded on factor three. The other 24(42.9\%) sorts did not significantly load on any of the three factors. This is partly explained by the very high threshold for acceptance of a factor loading (i.e, 0.7) which arises largely because of the small number of photographs in the Q-set.

The factor loadings are presented in Table 3. Table 3 shows that factors one and two are "bipolar" factors, which means there are two or more sorts having significant positive loadings on them as well as two or more sorts having significant negative loadings on them. The negatively loaded sorts represent a near reverse or mirror-image of the Q sort configuration compared to those of positively loaded sorts (Watts \& Stenner, 2012).

Table 3: Results of the $Q$ factor analysis

\begin{tabular}{|c|c|c|c|}
\hline Participant/sort & Factor 1 & Factor 2 & Factor 3 \\
\hline OHS7 & 0.9280 & -0.1172 & 0.1413 \\
\hline OHS12 & 0.8401 & 0.0221 & -0.3204 \\
\hline OHS14 & 0.9189 & 0.1505 & -0.1145 \\
\hline Cons3 & 0.8991 & 0.0639 & 0.2873 \\
\hline Cons4 & 0.8996 & 0.026 & 0.0806 \\
\hline Cons5 & 0.8704 & -0.0595 & -0.1143 \\
\hline Cons8 & 0.7468 & -0.4516 & 0.023 \\
\hline Cons10 & 0.7279 & 0.2902 & -0.2779 \\
\hline Eng3 & 0.7735 & -0.1057 & 0.2726 \\
\hline Eng10 & 0.7331 & 0.1313 & 0.4011 \\
\hline Eng14 & 0.9189 & 0.1505 & -0.1145 \\
\hline Arch13 & 0.9189 & 0.1505 & -0.1145 \\
\hline Arch14 & 0.7886 & -0.0479 & 0.2339 \\
\hline Cons9 & -0.7382 & -0.3704 & 0.1746 \\
\hline Eng2 & -0.7876 & -0.395 & 0.3752 \\
\hline OHS10 & 0.1390 & 0.9333 & 0.0908 \\
\hline Arch6 & 0.139 & 0.9333 & 0.0908 \\
\hline Arch15 & 0.2418 & 0.8961 & 0.1966 \\
\hline OHS4 & 0.0408 & -0.7515 & -0.5384 \\
\hline Eng11 & -0.0791 & -0.9253 & -0.0594 \\
\hline Arch1 & -0.4363 & -0.8352 & 0.1403 \\
\hline Arch8 & 0.1805 & -0.8148 & 0.1795 \\
\hline Arch9 & -0.1689 & -0.9292 & 0.1784 \\
\hline OHS1 & 0.1006 & 0.1549 & 0.9664 \\
\hline OHS6 & -0.2064 & -0.0722 & 0.8691 \\
\hline Eng5 & -0.1507 & 0.3721 & 0.8377 \\
\hline Eng7 & 0.4155 & 0.0893 & 0.7624 \\
\hline
\end{tabular}




\begin{tabular}{|l|l|l|l|}
\hline Eng12 & -0.0484 & 0.0603 & 0.9112 \\
\hline Arch2 & -0.0288 & -0.3089 & 0.8647 \\
\hline Arch4 & 0.6399 & 0.0266 & 0.7066 \\
\hline Arch12 & 0.1006 & 0.1549 & 0.9664 \\
\hline Cons2 & 0.5447 & 0.2129 & -0.7005 \\
\hline
\end{tabular}

\section{Factor interpretation}

Factor arrays were calculated for each cluster of participants. The factor arrays for each of the three participant clusters are provided in Table 4. A number of differences were observed. Participants in cluster one considered the concrete block wall façade system to be the least likely to produce accidental injury, rating the likelihood of this to be "rare." In contrast, participants in clusters two and three considered this façade system to be "certain" to produce accidental injury. Participants in cluster three considered the use of a pre-cast concrete panel system for a car park construction and the use of pre-cast concrete panels for housing to present the lowest likelihood of accidental injury. In contrast, participants in cluster one considered the likelihood of accidental injury arising from the use of a pre-cast concrete panel system for a car park construction to be "certain." Participants in cluster two considered the concrete and window panel façade system, the full storey prefabricated façade system, the glazed panel façade system and the mixed glass and concrete panel façade system to present the lowest likelihood of accidental injury. The other two clusters, one and three, agreed that the full storey prefabricated façade system and the glazed panel facade system presented a generally low likelihood of accidental injury, both rating these as unlikely. However, participants in clusters one and three considered the likelihood of accidental injury associated with the construction of a concrete and window panel façade system and a mixed glass and concrete panel façade system to be moderate (cluster one) or likely (cluster two).

\section{Table 4: Factor arrays for three participant clusters}

\begin{tabular}{|l|l|r|r|r|}
\hline & & \multicolumn{3}{|c|}{ Factor Arrays } \\
\hline No. & Photograph/building system & Cluster 1 & Cluster 2 & Cluster 3 \\
\hline 1 & F01 Precast concrete panel system for housing & 1 & 1 & -2 \\
\hline 2 & F02 Precast concrete panel system for car park & 2 & 0 & -2 \\
\hline 3 & F03 Concrete and window panel façade system & 0 & -2 & 1 \\
\hline 4 & F04 Full storey prefabricated façade system & -1 & -2 & -1 \\
\hline 5 & F05 Glazed panel façade system & -1 & -2 & -1 \\
\hline 6 & F06 Mixed glass and concrete panel façade system & 0 & -2 & 1 \\
\hline 7 & F09 In-situ RC walling & 1 & 1 & 0 \\
\hline 8 & F10 Concrete block wall façade system & -2 & 2 & 2 \\
\hline
\end{tabular}

\section{Qualitative data analysis}

The qualitative explanations provided by participants whose sorting patterns loaded on factors one, two and three were compared and analysed. Table 5 shows that participants in the three clusters used different attributes when thinking about the OHS implications of the façade systems. While there is some overlap and common reference to some of the attributes, (e.g. "complexity of construction" and "construction process" were used by people belonging to more than one cluster) the relative importance of these attributes varied between clusters. For example, "complexity of construction" was the most frequently cited attribute used by participants whose sorting pattern loaded on factor one, while it was the third most frequently cited attribute used by participants whose sorting patterns loaded on factor three. These 
differences in the relative weight placed on each attribute explain the overall significant differences in the sorting patterns between participants in the three groups.

The consideration of the different attributes and their relative frequencies can explain the differences in sorting patterns. For example, photographs depicting the use of a precast concrete panel system for housing and the use of a precast concrete panel system for the construction of a car park were considered to present the lowest likelihood of accidental injury by participants in cluster three, who made reference to the off-site manufacture of components reducing the need for manual processes and multiple trades on site. However, participants in clusters one and two rated the likelihood of injury resulting from these systems as "likely" and "certain" respectively. They explained these judgements in terms of the size, weight and momentum of the panels, and the potential severity of the consequence associated with an accident should it occur during the lifting and manoeuvring and temporary propping of these panels before fixing them into place. Participants in cluster one considered the concrete block wall façade as being the least likely to produce accidental injury, while participants in cluster three considered the likelihood of accidental injury associated with this system to be certain. The qualitative explanations revealed different attributes used by clusters one and three. Participants in cluster one made reference to the type of work platform available when assessing this system, judging it as safer than the others because the picture depicted a fully scaffolded structure. This scaffold was perceived to reduce the risk of falling from height. In contrast, participants in cluster three judged this façade system with reference to the density of the construction process, commenting that the number of small units, repetitive lifting and in-situ nature of the construction work increased the risk of accidental injury. For these participants' the focus was on the increased risk of a repetitive strain or manual handling injury. 
Table 5: Qualitative attributes framing participants' OHS perceptions

\begin{tabular}{|c|c|c|}
\hline Cluster & Most frequently used attributes & Example quotations \\
\hline 1 & $\begin{array}{l}\text { - Complexity of construction (few or many } \\
\text { processes/few or many interfaces) } \\
\text { - Component scale/size (small or large) } \\
\text { - Location of installation (inside or outside) } \\
\text { - Distance (separation) between plant/load } \\
\text { and workers/working platform } \\
\text { - Work platform (scaffolding or mechanical } \\
\text { elevated work platform) }\end{array}$ & $\begin{array}{l}\text { - "Risk is higher when you use different machinery } \\
\text { in a task, e.g. , three different people deal with } \\
\text { tasks, one inside, one outside, and one operates } \\
\text { the crane." } \\
\text { - "Lifting big precast panels is a high risk activity, a } \\
\text { mobile crane, props, parallels, and workers all } \\
\text { there, it is likely that things can get out of } \\
\text { control." } \\
\text { - "Now whereas these other ones are likely to be } \\
\text { done either within the building, this one, } \\
\text { particularly, it doesn't look like there's any crane } \\
\text { required, and it can all be done within the building } \\
\text { without having to go outside, and safety rails." } \\
\text { "People are not separated, work outside, multiple } \\
\text { layers of people and activities, there should have } \\
\text { been better way of designing façade and material } \\
\text { handling." } \\
\text { "This one here is probably a bit safer with the } \\
\text { scaffolding, the scaffolding there, because the } \\
\text { scaffold obviously doesn't give you the } \\
\text { opportunity to fall." }\end{array}$ \\
\hline 2 & $\begin{array}{l}\text { - Construction process (off site } \\
\text { prefabrication reduces people and } \\
\text { processes on site compared to in situ } \\
\text { construction) } \\
\text { - Control (off site production allows more } \\
\text { control) } \\
\text { - Types of building construction } \\
\text { (commercial versus domestic) }\end{array}$ & $\begin{array}{l}\text { - "Well this is a labour-intensive activity. Yes, and } \\
\text { you know, it's materials handled-manual } \\
\text { material handling, so someone could get a sore } \\
\text { back, hurt their back lifting things..." } \\
\text { - "These are all prefabricated items which would } \\
\text { have been the subject of shop drawings, and so } \\
\text { you would expect that the installation tolerances } \\
\text { would be fairly accurate." } \\
\text { "Commercial construction has, more controls in } \\
\text { place, more systematic procedures...domestic } \\
\text { construction is less systematic." }\end{array}$ \\
\hline 3 & $\begin{array}{l}\text { - Density of installation process (repetitive } \\
\text { processes with small pieces/some } \\
\text { processes with medium size pieces /fewer } \\
\text { processes with large pieces ) } \\
\text { - Construction process (off site } \\
\text { prefabrication reduces people and } \\
\text { processes on site compared to in situ } \\
\text { construction) } \\
\text { - Work level (at ground level/low height } \\
\text { versus work at height) } \\
\text { - Complexity of construction (single } \\
\text { system/trade versus multiple } \\
\text { systems/trades) } \\
\text { - Location of installation (install from } \\
\text { inside or outside) }\end{array}$ & $\begin{array}{l}\text { - "There is elements up and down, there is } \\
\text { construction workers, and there is a mobile crane } \\
\text { to install panels, all parallel, could cause incidents } \\
\text { when putting glass panels on a concrete wall, it is } \\
\text { harder to fix, there are a lot of things happening, } \\
\text { and the degree of difficulty is higher by putting } \\
\text { glass façade on concrete wall." } \\
\text { - "This prefabricated system is less manually } \\
\text { intensive." } \\
\text { - "For most part, people work on the ground, there } \\
\text { is no likelihood of a fall." } \\
\text { - "There are a lot of thing happening on-site, with } \\
\text { potential of fall, manual handling, fall objects, } \\
\text { height work." } \\
\text { - "In a system like this the guys are working from } \\
\text { inside the building so there's nobody hanging } \\
\text { outside the building and you've can put } \\
\text { protection up so everyone's working inside the } \\
\text { building." }\end{array}$ \\
\hline
\end{tabular}




\section{Discussion}

\section{Variation in mental models of OHS}

The research reveals significant variation in participants' mental models of OHS. Three distinct sorting pattern "types" are reflected in the factor analysis results. Within these factors (or clusters), participants share similar judgements about the relative likelihood of accidental injury associated with the façade systems depicted in the eight photographs. The qualitative explanatory data indicates that participants in these clusters use different frames of reference or attributes to understand OHS issues. These attributes can explain differences in participants' judgements of the likelihood of accidental injury associated with the façade systems. The existence of distinct and differing understandings of OHS is consistent with previous research showing that construction industry contributors do not hold consistent views about OHS (see, for example, Gambatese et al. 2008). However, the current findings differ slightly from those of Gambatese et al. (2008) in that the different viewpoints relating to OHS evident in our results cut across occupational or professional lines (see below). Gambatese et al. (2008) found a very high level of agreement about the design-relatedness of accidents was found within a group of OHS professionals, a moderate level of agreement was found within a group of designers and a low level of agreement was found within a group of construction professionals.

It is also noteworthy that each of the three clusters of participants with similar sorting patterns contained participants whose sorting pattern was the polar opposite of that of the majority of cluster members.

The extant literature establishes a strong link between SSMs in team-based work and performance outcomes. Our results suggest that individual members of construction project teams may have different mental models of OHS. Standifer and Bluedorn (2006) note that teams are composed of boundary-spanning individuals, each acting in the interests of their own organisations, but working together in a temporary project coalition. As such, different perspectives are to be expected.

\section{Professional similarities and differences}

The participant clusters produced by the $\mathrm{Q}$ factor analysis cut across occupational and professional groups. In terms of numbers, constructors were the dominant professional group in cluster one and architects were the dominant professional group in cluster two. However, both of these clusters also included participants from the other occupational or professional groups. Cluster three was dominated by design professionals, with three architects and three engineers among the nine participants, but this cluster also included OHS professionals and one constructor (although the single constructor in this cluster provided a sorting pattern that was the polar opposite of the other cluster members).

The mix of occupation al and professional group members in each of the clusters produced by the $\mathrm{Q}$ factor analysis suggests that characteristics other than professional education and socialisation shape the way that people understand and think about OHS. A post-hoc comparison of the experience of participants in each cluster was performed to explore the possible influence of years of experience. This revealed that participants in cluster two tended to have more years of industry experience (mean $=33.3$ years) than participants in cluster one (mean $=20.0$ years) or cluster three (mean $=16.8$ years). These differences were statistically 
significant at the 0.05 probability level. The fact that the sorting pattern types cut across occupational/professional grouping indicates that construction industry professionals should not be stereotyped according to their occupation or role. The results reveal that people sharing an occupation or profession do not necessarily think alike with regard to OHS. Nor do people from diverse professional backgrounds necessarily think differently about OHS.

\section{Implications for practice}

Given the established link between SMMs, team processes and performance, it is possible that extreme differences in SMMs could negatively impact on OHS performance in construction projects. The results indicate that the existence of a common understanding of OHS within construction project teams cannot be assumed. Rather, a diverse range of OHS perspectives is more likely to exist. Thus, steps to recognise, understand and manage the diversity of mental models relating to OHS in construction project teams may be helpful, particularly when making important decisions about the design or specification of a particular building system or component. For example, previous research has highlighted the importance of providing a construction perspective in pre-construction planning and design decision-making to facilitate designing for construction (see, for example, Gerth et al. 2013). Given the fact that construction professionals are likely to bring different experiences, knowledge and skills to construction project teams, understanding their mental models of OHS could provide valuable insight into potential OHS issues associated with choices made during the planning and design stages of a construction project and support the integration of OHS into early project decision-making.

The literature suggests several potentially useful strategies to aid in the development of SSMs in teams. Stout et al. (1999) report that engaging in high quality planning activities and high rates of information exchange in low workload conditions created higher level of "sharedness" in team members' mental models and produced significantly better performance during periods of high workload. They conclude that teams operating in complex and dynamic environments should invest time and effort: (i) setting project goals, (ii) creating an open environment in which task-related information is understood and shared, (iii) discussing the consequences associated with decisions and errors; and (iv) clarifying team members' roles and responsibilities (Stout et al. 1999). Planning for OHS in this way could potentially foster the development of SMMs relating to OHS in construction project teams.

Cross-training is another strategy recommended to develop shared knowledge structures in professionally diverse teams (Marks et al. 2002). Cross training is designed to provide team members with an appreciation and understanding of the roles and perspectives of others. It can be achieved by instruction, shadowing or role-modelling. Marks et al. (2002) report that various forms of cross-training supported the development of SMMs in teams engaged in dynamic tasks in challenging environments. These SMMs, in turn, improved team coordination and performance.

Cross training of this kind, can potentially improve team members' perspective-taking. Perspective-taking involves "actively considering a particular situation - or the world more generally - from another person's point of view" (Goldstein et al., 2014, p.942). An inability to take the perspective of others has been linked to individuals making erroneous attributions and being unable to recognise opportunities for mutual benefit (Tjosvold and Johnson, 1977). In contrast, effective perspective-taking is associated with improved inter-group relations, cooperation, communication, and conflict resolution (Trötschel et al., 2011; Galinsky \& Moskowitz, 2000). Our research findings suggest that strategies to help construction 
professionals to understand and see OHS from the perspective of other project team members could identify opportunities for OHS improvements that may not otherwise be apparent to decision-makers. But, as Boland \& Tenkasi (1995, p. 362) point out, "perspective - taking is never a one-to-one mapping. Members of the same community will not have full consensus, and members of different communities cannot simply adopt the meanings of others." There is a strong case for accepting and embracing different perceptions of OHS risk when making decisions to provide a more complete picture of unexpected risks. The use of perspective taking in forecasting or envisioning hazards is likely to be of significant benefit to construction project teams, for example, in the case of innovative design of buildings/structures or new combinations of existing structures, when OHS risks may not be so clearly identifiable or well understood. Research is ongoing at RMIT to ascertain whether codified multi-stakeholder knowledge can produce increasing 'sharedness' in construction project team members' mental models of OHS.

However, there are also dangers inherent in trying to achieve a single uniform knowledge structure about OHS. If SMMs are very strongly held and, if the team environment does not support "constructive confrontation" between team members, then excessive conformity in thinking (i.e, groupthink) can occur, resulting in less effective decision-making (Kellermans et al. 2008). Thus, fostering a team environment in which diverse opinions about OHS are recognised and can be aired, understood and used to make effective decisions is recommended.

\section{Implications for research}

The research demonstrated the viability of using a novel data collection approach, i.e, the use of a photographic Q-methodology, to explore construction industry participants' understandings of OHS risk. The photographic Q-methodology was positively received by the majority of research participants. The data captured by this method provides a detailed insight into differences and similarities in the way that construction industry professionals' think about the OHS implications associated with different building systems.

Notwithstanding the successful application of Q-methodology, the validity of different methods used for measuring SMMs needs to be carefully evaluated (Ross \& Allen, 2012). It is recommended that, in future research, the photographic Q-sort method be compared with other methods used to measure SMMs, e.g, concept mapping, paired ratings and causal mapping, to ascertain the convergent validity of the Q-methodology approach.

\section{Conclusions}

The research revealed three distinguishable and different sorting pattern types relating to OHS issues associated with the different façade systems. These types cut across the membership of the four occupational/professional groups represented in the research. These results suggest that no single way of thinking about OHS is likely to prevail in construction project teams. Rather, team members will make judgements about OHS risk based upon their individual frames of reference. It is likely to be helpful to analyse and understand these different frames when making important project decisions. Implementing high quality planning and communication activities to understand team members' mental models of OHS early in the project life cycle and identify points of similarity and difference is recommended. Strategies designed to help project team members to take the perspective of other project stakeholders and participants may also be beneficial in some circumstances. Professional members of a construction project team will see the inherent "riskiness" of choices concerning building systems and construction technologies in different ways. The input of a 
diversity of perspectives relating to OHS may, in fact, help team members to make better decisions in complex situations.

\section{Limitations and future research}

The research used a photographic Q-sort method to examine individual construction professionals' mental models of OHS. The experience of the construction professionals was collected in the research. However, to protect the anonymity of participants given the relatively small sample size, we did not collect demographic data relating to age, gender, highest degree earned, project experience or family arrangements. It is possible that these factors also influence mental models of OHS and therefore, these could be examined in future studies using larger sample sizes. The data reported was not collected from field-based construction project teams. Future research should examine the existence of SMMs relating to OHS in construction project teams. Scenario-based simulation and experimental research could also be undertaken in order to investigate the extent to which SMMs improve decisionmaking and OHS performance outcomes in construction professionals working on teambased tasks. Future research should also investigate the effects of SMMs in the presence and the absence of a normative environment that supports constructive confrontation, i.e, the airing and resolution of differences of opinion.

\section{Acknowledgement}

This work was supported by Cooperative Agreement Number U60 OH009761, under which RMIT is a subcontractor to Virginia Tech, from the US Centers for Disease Control and Prevention (CDC), National Institute for Occupational Safety and Health (NIOSH). Its contents are solely the responsibility of the authors and do not necessarily represent the official views of the CDC NIOSH.

\section{References}

Anandarajan, M., Paravastu, N., \& Simmers, C. A. (2006). Perceptions of Personal Web Usage in the Workplace: AQ-Methodology Approach. CyberPsychology \& Behavior, 9(3), 325-335.

Atkinson, A. R. and Westall, R., (2010), The relationship between integrated design and construction and safety on construction projects, Construction Management and Economics, 28, 1007-1017.

Baiden, B., K. \& Price, A. D. F., (2011), The effect of integration on project delivery team effectiveness, International Journal of Project Management, 29, 129-136.

Banks, A. P. \& Millward, L. J., (2007), Differentiating knowledge in teams: The effect of shared declarative and procedural knowledge on team performance, Group Dynamics: Theory, Research and Practice, 11, 95-106.

Boland, R. J., \& Tenkasi, R. V., (1995), Perspective making and perspective taking in communities of knowing, Organization Science, 6, 350-372.

Bowen, P. A., Edwards, P. J., \& Lingard, H. (2013). Workplace stress among construction professionals in South Africa: The role of harassment and discrimination, Engineering, Construction and Architectural Management, 20 (6), 620-635.

Brown, S.R. (1993). A primer on Q methodology. Operant Subjectivity, 16, 91-138.

Brown, S.R., (1970). On the use of variance designs in Q methodology. Psychological Record, 20, 179-189

Brown, S. R. (1980). Political subjectivity: Applications of Q methodology in political science. New Haven: Yale University Press.

Connon-Bowers, J. A., Salas, E. \& Converse, S. A., (1993), Shared mental models in expert team decision making, in N. J. Castellan Jr. (Ed), Current issues in individual and group decision making, Erlbaum, Hillsdale NJ. pp. 221-246.

DeChurch, L. A. \& Mesmer-Magnus, J. R., (2010), Measuring team mental models: A meta-analysis, Group Dynamics: Theory, Research and Practice, 14, 1-14.

Donaghy, R., (2009), One death is too many: Inquiry into the underlying causes of construction fatal accidents, Report to the Secretary of State for Work and Pensions, Crown Copyright, Office of Public Information, Richmond.

Driskell, J. E., Radtke, P. H. \& Salas, E., (2003), Virtual teams: Effects of technological mediation on team processes, Group Dynamics: Theory, Research and Practice, 7, 297-323. 
Driskell, J. E., Salas, E., \& Johnsoton, J. H., (1999), Does stress lead to a loss of team perspective? Group Dynamics, 3, 291-302.

Dryzek, J.S. \& Berejikian, J., 1993. Reconstructive Democratic Theory. The American Political Science Review, 87(1), pp.48-60.

Edwards, B. D., Day, E., A., Arthur, W. Jr \& Bell, S. T., (2006), Relationships among team ability composition, team mental models and team performance, Journal of Applied Psychology, 91, 727-736

Espevik, R., Johnson, B. H. \& Eid, J., (2011), Communication and performance in co-located and distributed teams: An issue of shared mental models of team members? Military Psychology, 23, 616-638.

Fairweather, J. R., Swaffield, S. R., \& Simmons, D. G. (1998). Understanding visitors' experiences in Kaikoura using photographs of landscapes and Q method Tourism Research and Education Centre (TREC) report no. 5: Lincoln University, Tourism Research and Education Centre.

Fisher, D. M., Bell, S. T., Dierdorff, E. C. \& Belohlav, J. A., (2012), Facet personality and surface-level diversity as team mental model antecedents: Implications for implicit coordination, Journal of Applied Psychology, 97, 825-841.

Galinsky, A. D. \& Moskowitz, G. B. (2000) Perspective-taking: Decreasing stereotype expression, stereotype accessibility and in-group favoritism, Journal of Personality and Social Psychology, 78, 708-724.

Gambatese, J.A., Behm, M., \& Rajendran S, (2008), Design's role in construction accident causality and prevention: perspectives from an expert panel, Safety Science, 43, 675-691.

Gerth, R., Boqvist, A., Bjelkemyr, M. \& Lindberg, B., (2013), Design for construction: utilizing production experiences in development, Construction Management and Economics, 31, 135-150.

Gherardi, S., Nicolini, D. \& Odella, F., (1998), What do you mean by safety? Conflicting perspectives on accident causation and safety management in a construction firm, Journal of Contingencies and Crisis Management, 6, 202-213.

Goldstein, N. J., Vezich, S. \& Shapiro, J. R., (2014), Perceived perspective taking: When others walk in our shoes, Journal of Personality and Social Psychology, 106, 941-960.

Green, R. (2005). Community perceptions of environmental and social change and tourism development on the island of Koh Samui, Thailand. Journal of Environmental Psychology, 25(1), 37-56.

Kellermanns, F. W., Floyd, S. W., Pearson, A. W. and Spencer, B., (2008), The contingent effect of constructive confrontation on the relationship between shared mental models and decision quality, Journal of Organizational Behavior, 29, 119-137.

Lawrence, P. R. \& Lorsch, J. W., (1969), Organization and environment: Managing differentiation and integration, Richard D. Irwin Inc., Homewood, Illinois.

Leung, M-Y., Chan, Y. S., \& Olomolaiye, P. (2008). Impact of stress on the performance of construction project managers, Journal of Construction Management and Engineering, 134, 644-652

Mathieu, J. E., Heffner, T. S., Goodwin, G. F., Salas, E. and Cannon-Bowers, J. A., (2000), The influence of

shared mental models on team process and performance, Journal of Applied Psychology, 85, 273-283.

Mathieu, J. E., Heffner, T. S., Goodwin, G. F., Cannon-Bowers, J. A. \& Salas, E., (2005), Scaling the quality of teamates' mental models: Equifinality and normative comparisons, Journal of Organizational Behavior, 26, 37-56.

Marks, M. A., Sabella, M. J., Burke, C. S. \& Zaccaro, S. J., (2002), The impact of cross-training on team effectiveness, Journal of Applied Psychology, 87, 3-13.

Mohammed, S., Kimoski, R. and Rentsch, J. R., (2000), The measurement of team mental models: We have no shared schema, Organizational Research Methods, 3, 123-165.

Richter, A. and Koch, (2004), Integration, differentiation and ambiguity in safety cultures, Safety Science, 42, 703-722.

Rouse, W. B. \& Morris, N. M. (1986), On looking into the black box: prospects and limits in the search for mental models, Psychological Bulletin, 100, 349-363.

Priemus, H. and Ale, B., (2010), Construction safety: An analysis of systems failure The case of the multifunctional Bos \& Lommerplein estate, Amsterdam, Safety Science, 48, 111-122.

Prussia, G. E., Brown, K. A. and Willis, P. G., (2003), Mental models of safety: do managers and employees see eye to eye?, Journal of Safety Research, 34, 143-156.

Resick, C. J., Dickson, M. W., Mitchelson, J. K., Allison, L. K. \& Clark, M. A., (2010), Team composition, cognition, and effectiveness: Examining mental model similarity and accuracy, Group Dynamics: Theory, Research and Practice, 14, 174-191.

Ross, S. \& Allen, N., (2012), Examining the convergent validity of shared mental model measures, Behavior Research, 44, 1052-1062.

Salas, E., Sims, D. E., and Burke, C. S., (2005), Is there a "big five" in teamwork? Small Group Research, 36, 555-599. 
Smith-Jensch, K. A., Campbell, G., Milanovich, D. M. and Reynolds, A. M., (2001), Measuring teamwork mental models to support training needs assessment, development and evaluation: Two empirical studies, Journal of Organizational Behavior, 22, 179-194.

Smith-Jentsch, K. A., Mathieu, J. E. \& Kraiger, K., (2005), Investigating linear and interactive effects of shared mental models on safety and efficiency in a field setting, Journal of Applied Psychology, 90, 523-535

Stagl, K. C., Salas, E., Rosen, M. A., Priest, H. A., Burke, C. S., Goodwin, G. F. \& Johnston, J. H., (2007), Distributed team performance: A multi-level review of distributed demography, and decision making, in F. Danserau \& F. J. Yammarino (Eds), Multi-level issues in organizations and time, JAI Press, Oxford, pp. 1158.

Standifer, R. \& Bluedorn, A., (2006), Alliance management teams and entrainment: Sharing temporal mental models, Human Relations, 59, 903-927.

Stainton Rogers, R., (1995), Q methodology, in Rethinking methods in psychology, in J.A. Smith, R. Harre \& L. Van Langenhove (Eds), Sage, Thousand Oaks, CA.

Stenner, P., Watts, S., \& Worrell, M. (2008). Q Methodology. In C. Willig \& W. Stainton-Rogers (Eds.), The SAGE Handbook of Qualitative Research in Psychology (pp. 215-239). London, UK: SAGE Publications Ltd.

Stout, R. J., Cannon-Bowers, J. A., Salas, E. \& Milanovich, D. M., (1999), Planning, shared mental models, and coordinated performance: An empirical link is established, Human Factors, 41, 61-71.

Tjosvold, D. and Johnson, D. W., (1977), Effects of controversy on cognitive perspective taking, Journal of Educational Psychology, 69, 679-685.

Trötschel, R., Huffmeier, J., Loschelder, D. D., Schwartz, K. \& Gollwitzer, P. M., (2011), Perspective taking as a means to overcome motivational barriers in negotiations: When putting oneself into the opponent's shoes helps to walk toward agreements, Journal of Personality and Social Psychology, 101(4), 771-790.

Waller, M. J., Gupta, N. \& Giambatista, R. C., (2004), Effects of adaptive behaviors and shared mental models on control crew performance, Management Science, 50, 1534-1544.

Watts, S., \& Stenner, P. (2005). Doing Q methodology: theory, method and interpretation. Qualitative Research in Psychology, 2(1), 67-91.

Watts, S., \& Stenner, P. (2012). Doing Q methodological research: Theory, method \& interpretation. Sage, London.

Webler, T., Danielson, S., \& Tuler, S. (2009). Using Q method to reveal social perspectives in environmental research. Social and Environmental Research Institute, Greenfield, MA. 